\title{
The Impact of Donor Type and ABO Incompatibility on Transfusion Requirements after Nonmyeloablative Hematopoietic Cell Transplantation (HCT)
}

\author{
Zejing Wang ${ }^{1,{ }^{*}}$, Mohamed L. Sorror ${ }^{1,3,{ }^{*}, \text { Wendy Leisenring }}{ }^{1,2}$, Gary Schoch ${ }^{1}$, David G. \\ Maloney ${ }^{1,3}$, Brenda M. Sandmaier ${ }^{1,3}$, and Rainer Storb ${ }^{1,3}$ \\ ${ }^{1}$ Division of Clinical Research, Fred Hutchinson Cancer Research Center, Seattle, WA 98109 \\ ${ }^{2}$ Biostatistics, University of Washington, School of Public Health \\ ${ }^{3}$ Department of Medicine, University of Washington, School of Medicine, Seattle, WA 98195
}

\section{Summary}

\begin{abstract}
We retrospectively analyzed transfusion requirements within the first 100 days among allogeneic hematopoietic cell transplantation (HCT) recipients with hematological malignancies given either myeloablative $(n=1353)$ or nonmyeloablative conditioning $(n=503)$. We confirmed that myeloablative recipients required more platelet and red blood cell (RBC) transfusions than nonmyeloablative recipients (both $P<0.0001$ ). Myeloablative patients given peripheral blood stem cells required less platelet transfusions $(P<0.0001)$ than those given marrow while RBC transfusion requirements did not differ significantly. Subsequent analyses were restricted to nonmyeloablative recipients. Related recipients required less platelet and RBC transfusions compared to unrelated recipients ( $P<0.0001$ for both), with comparable median numbers of transfused units. Major/bidirectionally ABO-mismatched recipients required more RBC transfusions than ABO-matched recipients $(P=0.006)$. Rates of graft rejection/failure, grades II-IV acute and chronic graft-versus-host-disease (GVHD), 2-year relapse, 3-year survivals and nonrelapse mortality were comparable among ABO-matched, minor-mismatched, and major/ bidirectionally mismatched recipients ( $P=0.93,0.72,0.57,0.36,0.17$ and 0.79 , respectively). Times to disappearance of anti-donor IgG and IgM isohemagglutinins among major/ bidirectionally ABO-mismatched recipients were affected by magnitude of pre-HCT titres $(P<0.001$ for both) but not GVHD ( $P=0.71$ and 0.78 , respectively). In conclusion, nonmyeloablative recipients required fewer platelet and RBC transfusions and among them, both unrelated and major/bidirectionally $\mathrm{ABO}$-mismatched recipients required more $\mathrm{RBC}$ transfusions. $\mathrm{ABO}$ incompatibility did not affect nonmyeloablative HCT outcomes.
\end{abstract}

\section{Keywords}

nonmyeloablative conditioning; allogeneic $\mathrm{HCT}$; ABO-incompatibility; transfusion

\footnotetext{
Corresponding author: Rainer Storb, Fred Hutchinson Cancer Research Center, Division of Clinical Research; 1100 Fairview Avenue N, D1-100, Seattle, WA 98109; Phone: (206) 667-4409; Fax: (206) 667-6124; rstorb@ fhcrc.org.

"The first two authors contributed equally.

Conflicts of Interest: The authors have no conflicts of interest to declare.
} 


\section{Introduction}

Allogeneic hematopoietic cell transplantation (HCT) is a potentially curative treatment for many patients with hematological malignancies. Historically, high-dose conditioning regimens have been used with the dual aims of disease eradication and host immunosuppression for acceptance of the allografts (Little \& Storb, 2002). Over the past several years, we have used a truly nonmyeloablative conditioning regimen in order to reduce the morbidity and mortality associated with high-intensity regimens and extend HCT to include older patients and those with comorbidities. The regimen consisted of $2 \mathrm{~Gy}$ total body irradiation (TBI) with or without $90 \mathrm{mg} / \mathrm{m}^{2}$ fludarabine (FLU), and post-grafting immunosuppression with mycophenolate mofetil (MMF) and either cyclosporine (CSP) or FK506 (Carella et al, 2000; McSweeney et al, 2001). An early study involving small numbers of patients showed reduced transfusion requirements among nonmyeloablative compared to myeloablative recipients of human leucocyte antigen (HLA)-identical sibling HCT (Weissinger et al, 2001). Other studies involving myeloablative HCT recipients showed that fewer transfusions were required for recipients of related compared to unrelated grafts (Anasetti et al, 1989; Mielcarek et al, 2000; Zaucha et al, 2002; Sorror et al, 2004). Whether or not HCT from unrelated donors affected transfusion requirements in the nonmyeloablative HCT setting remained to be evaluated.

Major ABO incompatibility between donors and recipients has been associated with delayed red blood cell recovery, transient pure red cell aplasia and, thereby, prolonged need for red blood cell (RBC) transfusions in the high-dose HCT setting (Bolan et al, 2001a, b; Worel et al, 2003; Griffith et al, 2005). Results on effects of ABO compatibility on HCT outcomes were not consistent, with some studies suggesting that $\mathrm{ABO}$ incompatibility increased overall mortality, graft-versus-host disease (GVHD) and graft rejection/failure following both nonmyeloablative and myeloablative HCT (Benjamin et al, 1999; Stussi et al, 2001; Stussi et al, 2002; Worel et al, 2003; Remberger et al, 2007), others suggesting a lower risk of relapse but little effect on overall survival, and yet others seeing no effects on HCT outcomes (Klumpp et al, 2006; Mielcarek et al, 2000; Mehta et al, 2002; Goldman et al, 2003; Seebach et al, 2005). Only limited information has been available on the impacts of $\mathrm{ABO}$ incompatibility on both $\mathrm{RBC}$ and platelet transfusion requirements in the nonmyeloablative HCT setting (Weissinger et al, 2001; Zaucha et al, 2002; Badros et al, 2002; Baron et al, 2006).

Here, we retrospectively analyzed $\mathrm{RBC}$ and platelet transfusion needs among a larger number of patients with hematological malignancies who received nonmyeloablative conditioning. We compared RBC and platelet transfusion needs among patients given grafts from related versus unrelated donors, and analyzed the effect of $\mathrm{ABO}$ incompatibility on transfusion requirements and nonmyeloablative HCT outcomes. In addition, we compared transfusion needs after nonmyeloablative and myeloablative HCT among concurrently transplanted patients.

\section{Materials and Methods}

\section{Patients}

The study analyzed RBC and platelet transfusion needs during the first 100 days among 1,856 consecutive patients with hematological malignancies who received either HLAmatched related or unrelated HCT after nonmyeloablative $(n=503)$, or myeloablative $(n=1353)$ conditioning regimens between December 1997 and February 2008 at the Fred Hutchinson Cancer Research Center (FHCRC) (Table I). Patients and donors were matched for HLA-A,-B, and -C antigens by either intermediate resolution DNA typing (to a level at 
least as sensitive as serology) or high-resolution techniques. HLA matching for HLA-DRB1 and -DQB1 was done at the allele level (Petersdorf et al, 1998).

The nonmyeloablative regimen consisted of $2 \mathrm{~Gy}$ TBI with or without fludarabine, 30mg/ $\mathrm{m}^{2} /$ day from days -4 to -2 , and postgrafting immunosuppression with MMF and CSP or FK506. Myeloablative conditioning consisted of bulsulfan and cyclophosphamide, or 1214.4 Gy fractionated TBI and cyclophosphamide. Post-grafting immunosuppression in myeloablative recipients consisted of methotrexate (MTX) or MMF plus CSP or FK506. Nonmyeloablative protocols were offered to patients who were either $>50$ years old or, if < 50 years old, had significant pre-existing medical problems or had preceding high-dose HCT.

\section{ABO-incompatible transplants}

ABO-incompatible transplantations were performed according to FHCRC standard practice guidelines (Rowley et al, 2000; Mielcarek et al, 2000). Minor ABO- mismatches were characterized by the presence of anti-recipient isohemagglutinins in donors, e.g., O-type donors and A-, B- or AB-type recipients; major ABO-mismatches included the presence of anti-donor isohemagglutinins in recipients, e.g., A-, B- or AB-type donors and O-type recipients; bidirectionally $\mathrm{ABO}$ - mismatches were characterized by the combination of major and minor ABO-mismatches, e.g., A-type donors and B-type recipients, or B-type donors and A-type recipients.

Standard practice guidelines (Rowley et al, 2000) for management of major ABO incompatibility at FHCRC were as follows: if marrow served as the source of stem cells, $\mathrm{RBC}$ depletion was performed in related transplants, and plasma exchange using donor type plasma was performed in recipients of unrelated transplants whenever anti-donor isohemagglutinins titres were greater than 1:16. If granulocyte colony-stimulating factor "mobilized" peripheral blood mononuclear cells served as the stem cell source, the product was infused without manipulation if the calculated RBC volume was less than $10 \mathrm{ml}$.

\section{Transfusion policies}

Platelet support was given when platelet counts were less than $10 \times 10^{9} / 1$ in the outpatient setting and less than $20 \times 10^{9} / 1$ in the inpatient setting or when patients had signs of bleeding. Patients received random donor platelets unless they developed refractoriness. Random platelets were either whole-blood pooled random platelets or random single-donor apheresis platelets. Before transplantation, all patients received leucocyte-reduced platelets. After transplantation, leucocyte reduction was no longer required. Packed RBCs were transfused when hematocrits were less than $26 \%$ or when patients were symptomatic.

Volume-reduced platelets were used to minimize the amount of isohemagglutinins in ABOmismatched platelet transfusions. For patients with minor ABO mismatches, posttransplantation platelet transfusions were of recipient (or $\mathrm{AB}$ ) type, and $\mathrm{RBC}$ transfusions were O-type; for patients with major $\mathrm{ABO}$-mismatches and bidirectional mismatches, posttransplantation platelet transfusions were of donor or AB-type as first choice, and $\mathrm{RBC}$ transfusions were O-type. Plasma was depleted when O-group platelets were used for A-, Bor AB-group recipients. All transfusions were irradiated. IgG and IgM isohemagglutinins titres were measured in recipients before transplant and followed weekly after transplant until titres were undetectable for two consecutive weeks (Buckner et al, 1978). Once hemagglutinin titres were undetectable, RBC transfusions were switched to donor type $\mathrm{RBCs}$. If bidirectionally $\mathrm{ABO}$ incompatibility was present, plasma exchange, if indicated, was performed with pooled $\mathrm{AB}$ plasma. Post-transplant $\mathrm{RBC}$ transfusion guidelines in this 
group of patients were according to major ABO-mismatched transplants. Erythropoietin was not used for the treatment of complications associated with ABO-incompatible HCT.

\section{Laboratory tests}

Complete blood counts were obtained frequently as indicated; serum lactate dehydrogenase and total bilirubin levels were obtained three times per week. Haptoglobin and direct antiglobulin testing were not performed routinely but performed if clinically indicated. The results of serological tests performed at the Puget Sound Blood Center (Seattle, WA, USA) were obtained retrospectively from transfusion records and patient charts.

\section{Statistical analysis}

Summary statistics such as median and ranges were presented. Unadjusted comparisons of proportions of patients requiring platelet and RBC transfusion support during the first 100 days after transplant were made between recipients of nonmyeloablative transplants and myeloablative transplants, and different subgroups among nonmyeloablative HCT recipients using $\chi^{2}$ tests. Among subjects who received at least one transfusion, the median number of days and units of platelet and RBC transfusions received were compared between the same groups using a Wilcoxon ranksum test. Cumulative incidences of the probability of disappearance of IgG and IgM isohemagglutinin titres, acute and chronic GVHD, graft rejection and relapse were calculated, treating death as a competing risk event for each outcome (Kalbfleisch \& Prentice, 1980). Survival curves were evaluated using the method of Kaplan and Meier. Univariate comparisons between cumulative incidence and survival curves were made using a logrank test. Cox proportional hazards models were used to evaluate potential multivariate effects of risk factors on disappearance of $\mathrm{IgG}$ and IgM isohemagglutinin titres and to evaluate hazard ratios (HR) and associated $95 \%$ confidence intervals (CI). All reported p-values are two-sided, with a significance level of 0.05 .

\section{Results}

\section{Pre-transplantation patient characteristics}

The characteristics of the patients treated with either myeloablative or nonmyeloablative conditioning are listed in Table I. The median age of patients given nonmyeloablative conditioning was 56.2 years compared to 42 years for myeloablative patients $(P<0.0001)$. Diagnoses among nonmyeloablative patients mainly included non-Hodgkin and Hodgkin lymphomas, acute and chronic leukemias, and multiple myeloma (MM), while those in myeloablative patients were mainly acute leukemia (AL), chronic myeloid leukemia (CML) and myelodysplasia (MDS). Among the 503 nonmyeloablative recipients, $52.7 \%$ had grafts from related donors and $47.3 \%$ had grafts from unrelated donors; $58.1 \%$ had grafts from ABO-compatible donors and $41.9 \%$ from ABO-incompatible donors, including $20.3 \%$ minor ABO-mismatches and $21.7 \%$ major plus bidirectionally ABO-mismatches. Among the 1,353 myeloablative recipients, $52.9 \%$ and $47.1 \%$, respectively, had grafts from related and unrelated donors; $51.2 \%, 22.1 \%$ and $26.7 \%$, respectively, had grafts from ABOmatched, minor $\mathrm{ABO}-$ mismatched and major plus bidirectionally $\mathrm{ABO}-$ mismatched donors.

\section{Comparing transfusion requirements in myeloablative and nonmyeloablative recipients}

Virtually all myeloablative patients received platelet (99\%) and RBC (96\%) transfusions compared to $36 \%$ and $75 \%$ of nonmyeloablative patients, respectively $(P<0.0001$ for both, Table II). Both platelets and RBC transfusion requirements declined over the 100-day time period, with the majority of transfusions given within the first 25 days. Among myeloablative patients, recipients of peripheral blood stem cells (PBSC) $(n=816)$ required fewer days and units of platelet transfusions, with medians of 4 days (range, 0-90) and 24 
units (range, 0-920), respectively, compared to recipients of bone marrow (BM, $\mathrm{n}=533$ ), with medians of 8 days (range, $0-83)$ and 44 units (range, $0-681)$, respectively $(P<0.0001$ for both), while RBC transfusion units and days did not differ significantly ( $\mathrm{P}=0.34$ and 0.06 , respectively). Thirty five percent and $74 \%$ of nonmyeloablative PBSC recipients $(\mathrm{n}=$ 492) required platelet and RBC transfusions compared to $99 \%$ and $97 \%$ myeloablative PBSC recipients, respectively $(P<0.0001$ for both). Nonmyeloablative PBSC recipients also required fewer days and units of both platelet and $\mathrm{RBC}$ transfusions compared to myeloablative PBSC recipients $(P=0.0003$ for both days and units of platelets transfusions, and $P=0.02$ and 0.01 for days and units of RBC transfusions, respectively)

Among those given transfusions, nonmyeloablative patients required fewer days of transfusion support, with a median of 3 days for platelets and 4 days for RBCs compared to medians of 6 days and 4 days, respectively, for myeloablative patients (Fig. 1A, $P<0.0001$ and $P=0.0007$, respectively). Transfused nonmyeloablative recipients required overall less platelet and RBC units than myeloablative patients (Fig. 1B and C), with medians of 18 platelet units (range, 4-538) and 7 RBC units (range, 1-41), compared to medians of 34 platelet units (range, 4-920) and 8 RBC units (range, 1-127), respectively $(P<0.0001$ and $P$ $=0.0002$, respectively). Furthermore, after adjusting for underlying diseases (AL, MDS, and CML vs. lymphoma, MM, and chronic lymphoblastic leukaemia), the myeloablative cohort still required overall more days $(P=0.001$ and 0.068 , respectively) and more units ( $P=$ 0.005 and 0.009 , respectively) of platelets and RBC transfusions.

\section{Transfusion requirements among nonmyeloablative HCT recipients}

Related vs. unrelated grafts-Twenty nine percent and $68 \%$ of related recipients required platelet and RBC transfusions, respectively, compared to $45 \%$ and $82 \%$ of unrelated recipients respectively (Table II, $P<0.0001$ for both). Both related and unrelated recipients required a median of 3 days of platelet transfusions $(P=0.43)$; however, related recipients required a median of 3 days of RBC transfusions compared to 5 days for unrelated recipients (Fig. 2A, $P=0.012$ ). The overall numbers of platelet and RBC units transfused were not significantly different among transfused related versus unrelated recipients (Fig. 2B and C), with medians of 16 (range, 4-538) versus 22 (range, 4-258) platelet units $(P=$ $0.48)$, and medians of 6 (range, $1-41)$ versus 8 (range, 1-40) RBC units $(P=0.063)$.

ABO-matched vs. ABO-mismatched recipients-Compared to major/ bidirectionally- $\mathrm{ABO}$ - mismatched recipients, $\mathrm{ABO}-$ matched recipients required slightly fewer platelet ( $34 \%$ versus $42 \%, P=0.14$ ) and significantly less RBC ( $70 \%$ versus $83 \%$, $p=0.006$ ) transfusions (Table II). There were no statistically significant differences between $\mathrm{ABO}-$ matched and minor $\mathrm{ABO}-$ mismatched recipients. Among patients who required transfusions, the median days for platelet transfusions were 3, 2, and 3.5 for ABO-matched, minor ABO-mismatched, and major/bidirectionally $\mathrm{ABO}-$ mismatched patients, respectively. But the differences between $\mathrm{ABO}$-matched patients and $\mathrm{ABO}$ - mismatched patients were not statistically significant $(P=0.55$ and 0.75 for minor and major/bidirectional $\mathrm{ABO}$ mismatched, respectively). The median numbers of days for RBC transfusions were 3 days for $\mathrm{ABO}$-matched and 3.5 days for minor $\mathrm{ABO}$-mismatched recipients compared to medians of 5 days for major/ bidirectionally ABO-mismatched recipients $(P=0.004$ and 0.026 respectively, [Fig. 3A]). Furthermore, major/bidirectionally ABO-mismatched recipients required a median of 19 (range, 4-538) platelet units compared to medians of 18 (range, 4258 ) and 12 (range, $4-158)$ units $(P=0.93$ and 0.40 , respectively) for ABO-matched and minor ABO-mismatched recipients (Fig. 3B). Medians of 6 units of RBC were given in ABO-matched (range, 1-38) and minor ABO-mismatched (range, 1-40) compared to 9 units (range, $1-41)$ in major/bidirectionally ABO-mismatched recipients, respectively $(P=0.026$ and 0.0095 , respectively [Fig. 3C]). 
Among major/bidirectionally ABO-mismatched recipients, unrelated grafts resulted in trends for increased platelet and RBC transfusion needs ( $46 \%$ and $86 \%$, respectively), compared to related grafts (38\% and 80\%, respectively, Table II) with $P=0.41$ and 0.37 for $\mathrm{RBC}$ and platelets, respectively.

Times to disappearance of anti-donor isohemagglutinin titres in ABOmismatched recipients-Among the 109 nonmyeloablative patients receiving major/ bidirectionally ABO-mismatched grafts, 98 had evaluable data on duration of persistence of anti-donor IgG and IgM isohemagglutinin titres after HCT. Among these, 93 subjects eventually reached disappearance of titres, and 9 had not yet reached disappearance of titres at their last follow up and thus were censored. Fig. 4 shows the cumulative incidence of disappearance of IgG and IgM titres with median days to disappearance of 48 and 47 days, respectively. There were no significant differences between recipients of related compared to unrelated grafts ( $P=0.40$ and 0.35 , for $\operatorname{IgG}$ and $\operatorname{IgM}$, respectively).

A Cox regression model was used to more precisely examine how the magnitude of antidonor isohemagglutinin titres at HCT affected the times to disappearance of titres after HCT. To this end, the quartiles of pre-HCT titres were included as categorical covariates. Higher pre-transplantation IgG and IgM titres were statistically significantly associated with longer persistence of titres $(P<0.001$ for both, Fig. 5). We also evaluated whether the impact of donor type on the hazards of titre disappearance was impacted by adjustment for pre-HCT titres. No significant differences were detected between related and unrelated grafts $(P=0.957$ and 0.743 for $\operatorname{IgG}$ and $\operatorname{IgM}$, respectively), though impact of pre-HCT titres remained significant.

We had suggested that graft-versus-plasma cell effects influenced the clearance rate of isohemagglutinins titres in the myeloablative setting (Mielcarek et al, 2000). In Cox regression analysis adjusted for pre-HCT titre levels, we found no statistically significant differences in the likelihood of reaching titre endpoints among nonmyeloablative recipients of major/bidirectionally ABO-mismatched grafts who experienced grades II-IV compared to those with grades $0-1$ acute GVHD ( $P=0.901$ and 0.858 for $\operatorname{IgG}$ and $\operatorname{IgM}$, respectively).

ABO-incompatibility and HCT outcomes-Cumulative incidences of graft rejection/ failure among ABO-matched, minor-mismatched, and major/bidirectionally-mismatched patients were comparable at $4.8 \%, 3.9 \%$ and $5.0 \%$, respectively (Table III, $P=0.93$ ). Similarly, no statistically significant differences were detected in incidences of grades II-IV acute GVHD and extensive chronic GVHD as stratified by degree of ABO-matching/ mismatching (Table III, $P=0.72$ and 0.57 , respectively). Also, the cumulative incidences of relapse of underlying malignancies at 2 years after HCT did not differ between the three patient groups $(P=0.36)$. Finally, 3-year survival (Fig. $6, P=0.17)$ and non-relapse mortality (Table III, $P=0.79$ ) rates among nonmyeloablative patients, as stratified by ABOmatching/mismatching, were not statistically significantly different among the groups.

\section{Discussion}

The present study included almost 1,900 concurrently transplanted patients, and confirmed earlier findings by us (Weissinger et al, 2001) and others (Ivanov et al, 2004; Le Blanc et al, 2004) that patients given nonmyeloablative conditioning before allogeneic HCT required significantly fewer platelet and RBC transfusions than myeloablative recipients.

Specifically, 64\% nonmyeloablative patients never needed platelet transfusions, and $24 \%$ did not require RBC transfusions compared to $1 \%$ and $4 \%$ of myeloablative patients, respectively. Given both the larger proportion of marrow grafts among myeloablative recipients and their greater transfusion requirements compared to PBSC grafts, we repeated 
the comparison with the focus on PBSC recipients and found the findings did not change. Further, among transfused nonmyeloablative patients, the numbers of platelet and RBC units were significantly lower than among their myeloablative counterparts. The differences in underlying disease diagnoses did not affect transfusion requirement between the two groups. There were at least two reasons for the decreased transfusion requirements. First, unlike a myeloablative regimen, the combination of $2 \mathrm{~Gy} \mathrm{TBI} \pm$ fludarabine did not cause major marrow damage, and host hematopoiesis continued until gradually being replaced by donor hematopoiesis. Second, other reasons for increased transfusion needs in myeloablative patients, such as gastrointestinal damage, veno-occlusive disease of the liver, diffuse alveolar hemorrhage, regimen-related hemorrhagic cystitis, and bacterial sepsis, were either absent or significantly decreased in nonmyeloablative patients (Hogan et al, 2004; Junghanss et al, 2002; Chien et al, 2005; Sorror et al, 2004; Diaconescu et al, 2004). The decreased transfusion requirements among nonmyeloablative recipients were seen even though patients were older, more heavily pretreated, and generally in worse medical condition.

Among patients given nonmyeloablative conditioning, those with unrelated grafts required more days of RBC but not platelet transfusions, while overall numbers of transfused platelet and $\mathrm{RBC}$ units were not statistically different between the two cohorts. Previous findings in myeloablative recipients included both increased $\mathrm{RBC}$ and platelet requirements after unrelated grafts, which were thought to be due to accelerated elimination of host hematopoiesis and more frequent, more severe and earlier-onset of acute GVHD resulting from greater non-HLA histocompatibility disparities in the unrelated setting (Mielcarek $e t$ $a l$, 2000). Perhaps the almost uniform use of PBSC grafts among current nonmyeloablative recipients helped to minimize these previously observed differences.

Unsurprisingly, and consistent with previous reports in both reduced-intensity conditioning (Zaucha et al, 2002; Worel et al, 2003; Canals et al, 2004) and myeloablative settings (Mielcarek et al, 2000; Seebach et al, 2005), patients with major/bidirectionally ABOincompatibilities required more $\mathrm{RBC}$ transfusions than $\mathrm{ABO}$-compatible and minor $\mathrm{ABO}-$ mismatched recipients. This resulted from extended persistence of host plasma cells generating anti-donor isohemagglutinins (Griffith et al, 2005), Among major ABOincompatible recipients, the extent of RBC support depended on the magnitude of anti-donor isohemagglutinins titres at the time of HCT, which was a major factor in the duration of persistence of such titres. Median times for disappearances of titres among recipients of related and unrelated grafts were comparable, at 47 and 48 days, respectively, for IgM and $\mathrm{IgG}$. The higher platelet transfusion requirements in major/bidirectionally ABO-mismatched recipients could be explained by the reported variable expression of group A and group B substances on platelets (Curtis \& McFarland, 2009), which might make donor platelets targets for the same isohemagglutinins that lysed donor RBC.

A previous study (Mielcarek et al, 2000) in 383 myeloablative recipients had suggested that graft-versus-plasma cell effects determined the tempo of disappearance of anti-donor titres; however, a correlation between GVHD and disappearance of titres was not found in the current nonmyeloablative patients. The difference in results might have been due to smaller current patient numbers, differences in GVHD prophylaxis, and higher rates of severe GVHD among myeloablative patients (Mielcarek et al, 2000).

Consistent with our previous study of 1,676 myeloablative recipients (Mielcarek et al, 2000) and two smaller studies in patients given nonmyeloablative, reduced-intensity or myeloablative conditioning regimens by Canals et al. and Goldman et al. (Zaucha et al, 2002; Goldman et al, 2003; Worel et al, 2003; Canals et al, 2004; Resnick et al, 2008), the current study of nonmyeloablative recipients failed to show significant associations between 
ABO-mismatching and HCT outcomes, including rates of engraftment, acute and chronic GVHD, disease relapse, survival and non-relapse mortality. This did not surprise us given that group A and B antigens have not been considered bona fide transplantation antigens. In contrast, studies reported by Worel et al and Resnick et al. (Worel et al, 2003; Resnick et al, 2008; Zaucha et al, 2002) indicated increases in non-relapse mortality with major ABOmismatched grafts, which the latter authors interpreted to be due to increased GVHD-related mortality. Variable associations between ABO-mismatching and HCT outcomes have been reported in myeloablative HCT settings. A Center for International Blood and Marrow Transplant Research analysis (Seebach et al, 2005), while detecting no differences in survival, showed an increase in grades III-IV acute GVHD in bidirectionally ABOmismatched recipients. Stussi et al., (2002), on the other hand, reported lower overall survival in a small group of recipients given bidirectionally ABO-mismatched grafts. The authors attributed their findings to synergistic adverse effects of both major and minor ABOincompatibilities (Stussi et al, 2002). An earlier study in patients given T-cell-depleted grafts reported an increase in grades II-IV acute GVHD associated with minor ABOmismatched but not bidirectionally-mismatched grafts (Keever-Taylor et al, 2001). The authors stated that "the mechanism behind the association of minor $\mathrm{ABO}$ disparity with acute GVHD was not clear." A decreased disease relapse rate in ABO-mismatched patients with AML in first complete remission and improved event-free survival were reported by Mehta et al. (2002), with no detection of differences in acute or chronic GVHD. The authors attributed their findings to enhanced graft-versus-leukemia effects by immune reactions directed at ABO-mismatched grafts. Finally, Remberger et al. (2007) observed increased rejections among $\mathrm{ABO}$-mismatched recipients, which they thought were due to binding of anti-donor $\mathrm{A} / \mathrm{B}$ antibodies to $\mathrm{A} / \mathrm{B}$ antigens absorbed on neutrophils or their precursors, which eventually led to their elimination or suppression. The reasons for the differences in outcomes among the various reports were not obvious, but might have to do with differences in conditioning regimens, GVHD prophylaxis, multi-centre effects, and relatively small patient numbers in some of the studies.

\section{Acknowledgments}

We thank the medical, nursing, and clinical and data processing teams for their dedicated care of patients and for their invaluable help in making the study possible. We also thank S Carbonneau, H Crawford, B Larson, K Carbonneau, J Fleenor and D Gayle for administrative assistance and manuscript preparation.

This work was supported by NIH grants CA78902, CA018029, CA15704 and HL36444.

\section{References}

Anasetti C, Amos D, Beatty PG, Appelbaum FR, Bensinger W, Buckner CD, Clift R, Doney K, Martin PJ, Mickelson E, Nisperos B, O’Quigley J, Ramberg R, Sanders JE, Stewart P, Storb R, Sullivan KM, Witherspoon RP, Thomas ED, Hansen JA. Effect of HLA compatibility on engraftment of bone marrow transplants in patients with leukemia or lymphoma. New England Journal of Medicine. 1989; 320:197-204. [PubMed: 2643045]

Badros A, Tricot G, Toor A, Morris C, Guo C, Munshi N, Barlogie B, Cottler-Fox M. ABO mismatch may affect engraftment in multiple myeloma patients receiving nonmyeloablative conditioning. Transfusion. 2002; 42:205-209. [PubMed: 11896336]

Baron F, Vanstraelen G, Beguin Y. Transfusions after nonmyeloablative or reduced-intensity conditioning regimens. Leukemia. 2006; 20:2081-2086. [PubMed: 17039229]

Benjamin RJ, McGurk S, Ralston MS, Churchill WH, Antin JH. ABO incompatibility as an adverse risk factor for survival after allogeneic bone marrow transplantation. Transfusion. 1999; 39:179_ 187. [PubMed: 10037129] 
Bolan CD, Childs RW, Procter JL, Barrett AJ, Leitman SF. Massive immune haemolysis after allogeneic peripheral blood stem cell transplantation with minor ABO incompatibility. British Journal of Haematology. 2001a; 112:787-795. [PubMed: 11260085]

Bolan CD, Leitman SF, Griffith LM, Wesley RA, Procter JL, Stroncek DF, Barrett AJ, Childs RW. Delayed donor red cell chimerism and pure red cell aplasia following major ABO-incompatible nonmyeloablative hematopoietic stem cell transplantation. Blood. 2001b; 98:1687-1694. [PubMed: 11535498]

Buckner CD, Clift RA, Sanders JE, Williams B, Gray M, Storb R, Thomas ED. ABO-incompatible marrow transplants. Transplantation. 1978; 26:233-238. [PubMed: 30194]

Canals C, Muniz-Diaz E, Martinez C, Martino R, Moreno I, Ramos A, Arilla M, Boto N, Pastoret C, Remacha A, Sierra J, Madoz P. Impact of ABO incompatibility on allogeneic peripheral blood progenitor cell transplantation after reduced intensity conditioning. Transfusion. 2004; 44:16031611. [PubMed: 15504166]

Carella AM, Cavaliere M, Corsetti MT, Lerma E. Allografting with immunosuppressive conditioning of low-dose fludarabine-cyclophosphamide after autografting. Blood. 2000; 96(Part 1) 553a, \#2376 (Abstract).

Chien JW, Maris MB, Sandmaier BM, Maloney DG, Storb RF, Clark JG. Comparison of lung function after myeloablative and 2 Gy of total body irradiation-based regimens for hematopoietic stem cell transplantation. Biology of Blood and Marrow Transplantation. 2005; 11:288-296. [PubMed: 15812394]

Curtis, BR.; McFarland, JG. Platelet immunology and alloimmunization. In: Simon, TL.; Snyder, EL.; Solheim, BG.; Stowell, CP.; Strauss, RG.; Petrides, M., editors. Rossi's Principles of Transfusion Medicine. Oxford, UK: Blackwell Publishing Ltd.; 2009. p. 168

Diaconescu R, Flowers CR, Storer B, Sorror ML, Maris MB, Maloney DG, Sandmaier BM, Storb R. Morbidity and mortality with nonmyeloablative compared to myeloablative conditioning before hematopoietic cell transplantation from HLA matched related donors. Blood. 2004; 104:1550 1558. [PubMed: 15150081]

Goldman J, Liesveld J, Nichols D, Heal J, Blumberg N. ABO incompatibility between donor and recipient and clinical outcomes in allogeneic stem cell transplantation. Leukemia Research. 2003; 27:489-491. [PubMed: 12648507]

Griffith LM, McCoy JP Jr, Bolan CD, Stroncek DF, Pickett AC, Linton GF, Lundqvist A, Srinivasan R, Leitman SF, Childs RW. Persistence of recipient plasma cells and anti-donor isohaemagglutinins in patients with delayed donor erythropoiesis after major ABO incompatible non-myeloablative haematopoietic cell transplantation. British Journal of Haematology. 2005; 128:668-675. [PubMed: 15725089]

Hogan WJ, Maris M, Storer B, Sandmaier BM, Maloney DG, Schoch HG, Woolfrey AE, Shulman HM, Storb R, McDonald GB. Hepatic injury after nonmyeloablative conditioning followed by allogeneic hematopoietic cell transplantation: a study of 193 patients. Blood. 2004; 103:78-84. [PubMed: 12969980]

Ivanov V, Faucher C, Mohty M, Bilger K, Ladaique P, Sainty D, Arnoulet C, Chabannon C, Vey N, Camerlo J, Bouabdallah R, Maraninchi D, Bardou VJ, Blaise D. Decreased RBCTs after reduced intensity conditioning allogeneic stem cell transplantation: predictive value of prior $\mathrm{Hb}$ level. Transfusion. 2004; 44:501-508. [PubMed: 15043564]

Junghanss C, Marr KA, Carter RA, Sandmaier BM, Maris MB, Maloney DG, Chauncey T, McSweeney PA, Storb R. Incidence and outcome of bacterial and fungal infections following nonmyeloablative compared with myeloablative allogeneic hematopoietic stem cell transplantation: a matched control study. Biology of Blood and Marrow Transplantation. 2002; 8:512-520. [PubMed: 12374456]

Kalbfleisch, JD.; Prentice, RL. The Statistical Analysis of Failure Time Data. New York: John Wiley \& Sons; 1980.

Keever-Taylor CA, Bredeson C, Loberiza FR, Casper JT, Lawton C, Rizzo D, Burns WH, Margolis DA, Vesole DH, Horowitz M, Zhang MJ, Juckett M, Drobyski WR. Analysis of risk factors for the development of GVHD after T cell-depleted allogeneic BMT: effect of HLA disparity, ABO incompatibility, and method of T-cell depletion. Biology of Blood and Marrow Transplantation. 2001; 7:620-630. [PubMed: 11760150] 
Klumpp TR, Herman JH, Ulicny J, Emmons RV, Martin ME, Mangan KF. Lack of effect of donorrecipient $\mathrm{ABO}$ mismatching on outcome following allogeneic hematopoietic stem cell transplantation. Bone Marrow Transplantation. 2006; 38:615-620. [PubMed: 16964267]

Le Blanc K, Remberger M, Uzunel M, Mattsson J, Barkholt L, Ringden O. A comparison of nonmyeloablative and reduced-intensity conditioning for allogeneic stem-cell transplantation. Transplantation. 2004; 78:1014-1020. [PubMed: 15480167]

Little M-T, Storb R. History of haematopoietic stem-cell transplantation. Nature Reviews Cancer. 2002; 2:231-238.

McSweeney PA, Niederwieser D, Shizuru JA, Sandmaier BM, Molina AJ, Maloney DG, Chauncey TR, Gooley TA, Hegenbart U, Nash RA, Radich J, Wagner JL, Minor S, Appelbaum FR, Bensinger WI, Bryant E, Flowers MED, Georges GE, Grumet FC, Kiem H-P, Torok-Storb B, Yu C, Blume KG, Storb RF. Hematopoietic cell transplantation in older patients with hematologic malignancies: replacing high-dose cytotoxic therapy with graft-versus-tumor effects. Blood. 2001; 97:3390-3400. [PubMed: 11369628]

Mehta J, Powles R, Sirohi B, Treleaven J, Kulkarni S, Saso R, Tait D, Singhal S. Does donor-recipient ABO incompatibility protect against relapse after allogeneic bone marrow transplantation in first remission acute myeloid leukemia? Bone Marrow Transplantation. 2002; 29:853-859. [PubMed: 12058235]

Mielcarek M, Leisenring W, Torok-Storb B, Storb R. Graft-versus-host disease and donor-directed hemagglutinin titers after $\mathrm{ABO}$-mismatched related and unrelated marrow allografts: evidence for a graft-versus-plasma cell effect. Blood. 2000; 96:1150-1156. [PubMed: 10910936]

Petersdorf EW, Gooley TA, Anasetti C, Martin PJ, Smith AG, Mickelson EM, Woolfrey AE, Hansen JA. Optimizing outcome after unrelated marrow transplantation by comprehensive matching of HLA class I and II alleles in the donor and recipient. Blood. 1998; 92:3515-3520. [PubMed: 9808542]

Remberger M, Watz E, Ringden O, Mattsson J, Shanwell A, Wikman A. Major ABO blood group mismatch increases the risk for graft failure after unrelated donor hematopoietic stem cell transplantation. Biology of Blood and Marrow Transplantation. 2007; 13:675-682. [PubMed: 17531777]

Resnick IB, Tsirigotis PD, Shapira MY, Aker M, Bitan M, Samuel S, Abdul-Hai A, Ackerstein A, Or $\mathrm{R}$, Slavin S. ABO incompatibility is associated with increased non-relapse and GVHD related mortality in patients with malignancies treated with a reduced intensity regimen: a single center experience of 221 patients. Biology of Blood and Marrow Transplantation. 2008; 14:409-417. [PubMed: 18342783]

Rowley SD, Liang PS, Ulz L. Transplantation of ABO-incompatible bone marrow and peripheral blood stem cell components. Bone Marrow Transplantation. 2000; 26:749-757. [PubMed: 11042656]

Seebach JD, Stussi G, Passweg JR, Loberiza FR Jr, Gajewski JL, Keating A, Goerner M, Rowlings PA, Tiberghien P, Elfenbein GJ, Gale RP, van Rood JJ, Reddy V, Gluckman E, Bolwell BJ, Klumpp TR, Horowitz MM, Ringden O, Barrett AJ. ABO blood group barrier in allogeneic bone marrow transplantation revisited. Biology of Blood and Marrow Transplantation. 2005; 11:10061013. [PubMed: 16338623]

Sorror ML, Maris MB, Storer B, Sandmaier BM, Diaconescu R, Flowers C, Maloney DG, Storb R. Comparing morbidity and mortality of HLA-matched unrelated donor hematopoietic cell transplantation after nonmyeloablative and myeloablative conditioning: influence of pretransplant comorbidities. Blood. 2004; 104:961-968. [PubMed: 15113759]

Stussi G, Seebach L, Muntwyler J, Schanz U, Gmur J, Seebach JD. Graft-versus-host disease and survival after ABO-incompatible allogeneic bone marrow transplantation: a single-centre experience. British Journal of Haematology. 2001; 113:251-253. [PubMed: 11328309]

Stussi G, Muntwyler J, Passweg JR, Seebach L, Schanz U, Gmur J, Gratwohl A, Seebach JD. Consequences of ABO incompatibility in allogeneic hematopoietic stem cell transplantation. Bone Marrow Transplantation. 2002; 30:87-93. [PubMed: 12132047]

Weissinger F, Sandmaier BM, Maloney DG, Bensinger WI, Gooley T, Storb R. Decreased transfusion requirements for patients receiving nonmyeloablative compared with conventional peripheral 
blood stem cell transplants from HLA-identical siblings. Blood. 2001; 98:3584-3588. [PubMed: 11739160]

Worel N, Kalhs P, Keil F, Prinz E, Moser K, Schulenburg A, Mitterbauer M, Mannhalter C, Mayr WR, Schwarzinger I, Hocker P, Lechner K, Greinix HT. ABO mismatch increases transplant-related morbidity and mortality in patients given nonmyeloablative allogeneic HPC transplantation. Transfusion. 2003; 43:1153-1161. [PubMed: 12869124]

Zaucha JM, Mielcarek M, Takatu A, Little M-T, Gooley T, Baker J, Maloney DG, Sandmaier BM, Maris M, Chauncey T, Storb R, Torok-Storb B. Engraftment of early erythroid progenitors is not delayed after non-myeloablative major ABO-incompatible haematopoietic stem cell transplantation. British Journal of Haematology. 2002; 119:740-750. [PubMed: 12437653] 

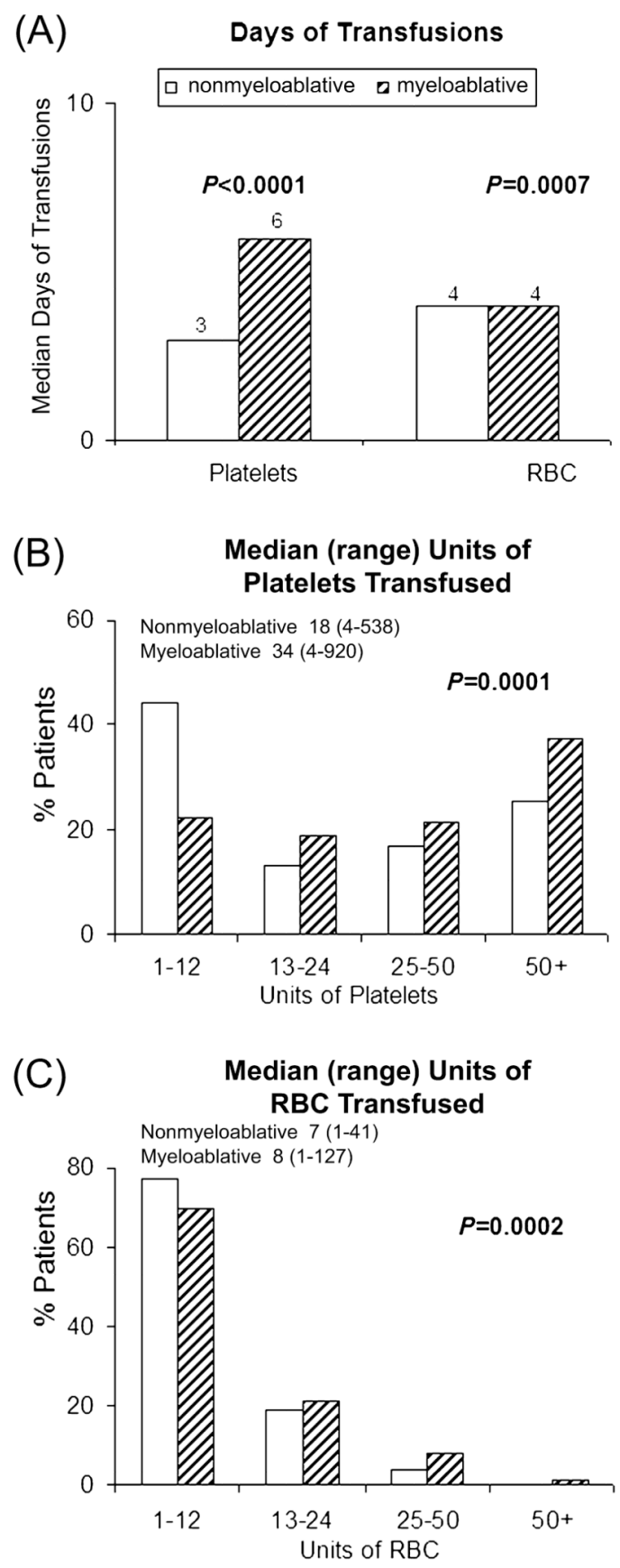

Fig. 1. Comparisons of platelet and RBC (red blood cells) transfusions between nonmyeloablative and myeloablative HCT patients who received at least one transfusion Nonmyeloablative recipients required less days of transfusion $(\mathbf{A})$ and units of both platelets (B) and $\operatorname{RBC}(\mathbf{C})$. 

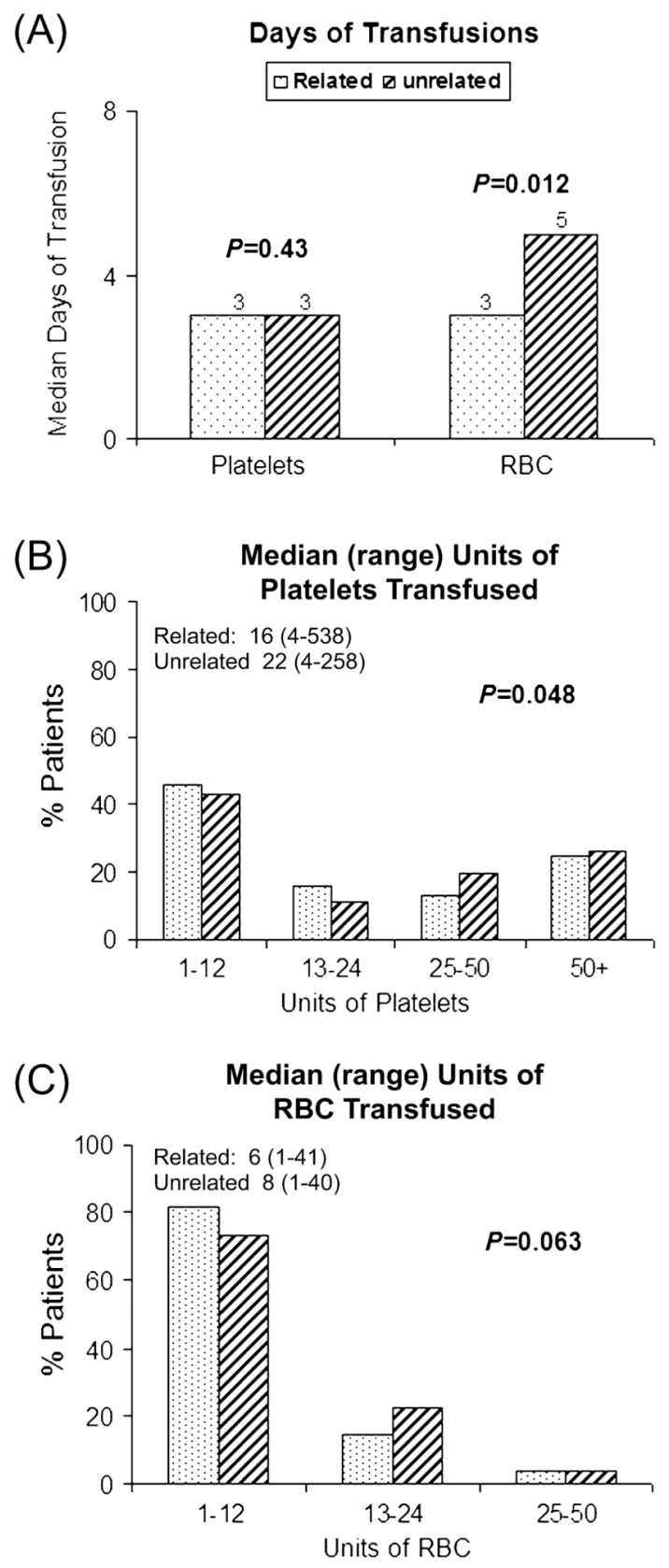

Fig. 2. Comparison of platelet and RBC transfusions among related and unrelated nonmyeloablative patients who received at least one transfusion

Recipients given related grafts required less days of RBC transfusions (A). The days of platelet and the units of transfused platelets $(\mathbf{B})$ and RBC (C) were not significantly different between the two groups. 


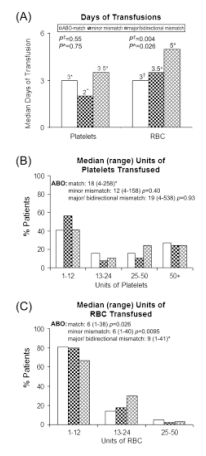

Fig. 3. Influence of ABO-incompatibility on Platelets and RBC transfusion requirements among nonmyeloablative HCT patients who received at least one transfusion

(A) Recipients given major/bidirectionally ABO-mismatched grafts required more days of RBC transfusion than recipients given ABO-matched or minor mismatched grafts $(P=0.004$ and 0.026, respectively); (B) No significant difference between platelet units required by ABO-matched and -mismatched HCT recipients; $(\mathbf{C})$ major/bidirectionally ABOmismatched HCT required significantly more RBC transfusion units than the other two groups. *Reference group for comparisons. 


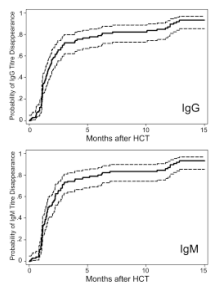

Fig. 4. Patients with nonmyeloablative conditioning regimens Cumulative incidences (solid lines) with 95\% confidence interval (dashed lines) of disappearances of anti-donor $\mathrm{IgG}$ and $\mathrm{IgM}$ isohemagglutinin titres among 98 recipients of major/bidirectionally ABO-mismatched grafts. 

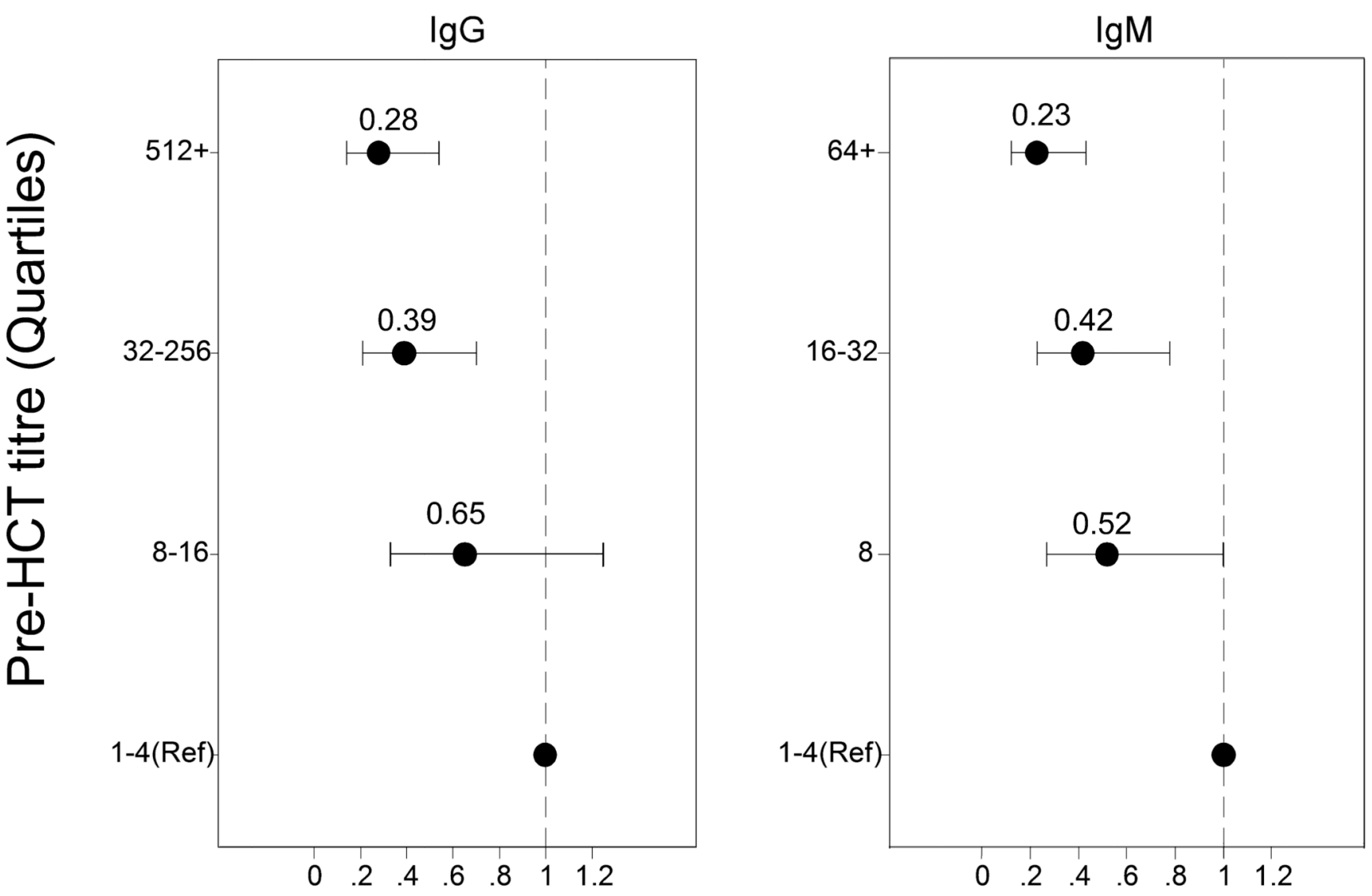

\section{Hazard Ratio for Post-HCT Titre Disappearance}

Fig. 5. Impact of pre-HCT titre levels on post-HCT titre disappearance among major $\mathrm{ABO} /$ Bidirectionally mismatched recipients given nonmyeloablative conditioning

Hazard ratios $(\bullet)$ and $95 \%$ CIs (-) for the hazard of post-HCT disappearance of IgG (left panel) and IgM (right panel) titres for increasing quartiles of pre-HCT IgG and IgM titre levels, respectively, as compared to the lowest quartile for each ( $\mathrm{p}<0.001$ for both). 


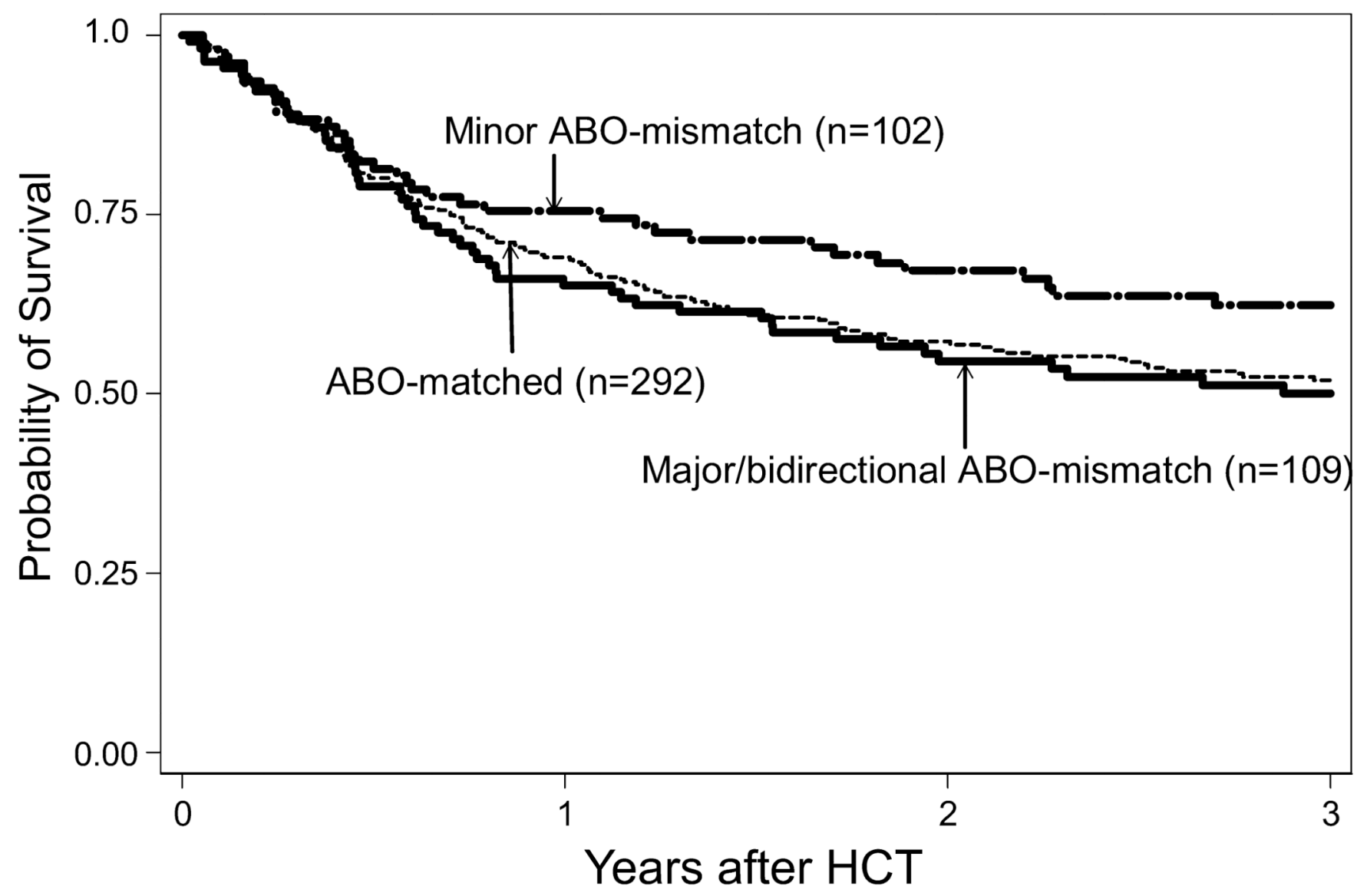

Fig. 6. Impact of ABO-compatibility on survival among nonmyeloablative HCT recipients No statistically significant differences were observed among the three cohorts $(P=0.17)$. 


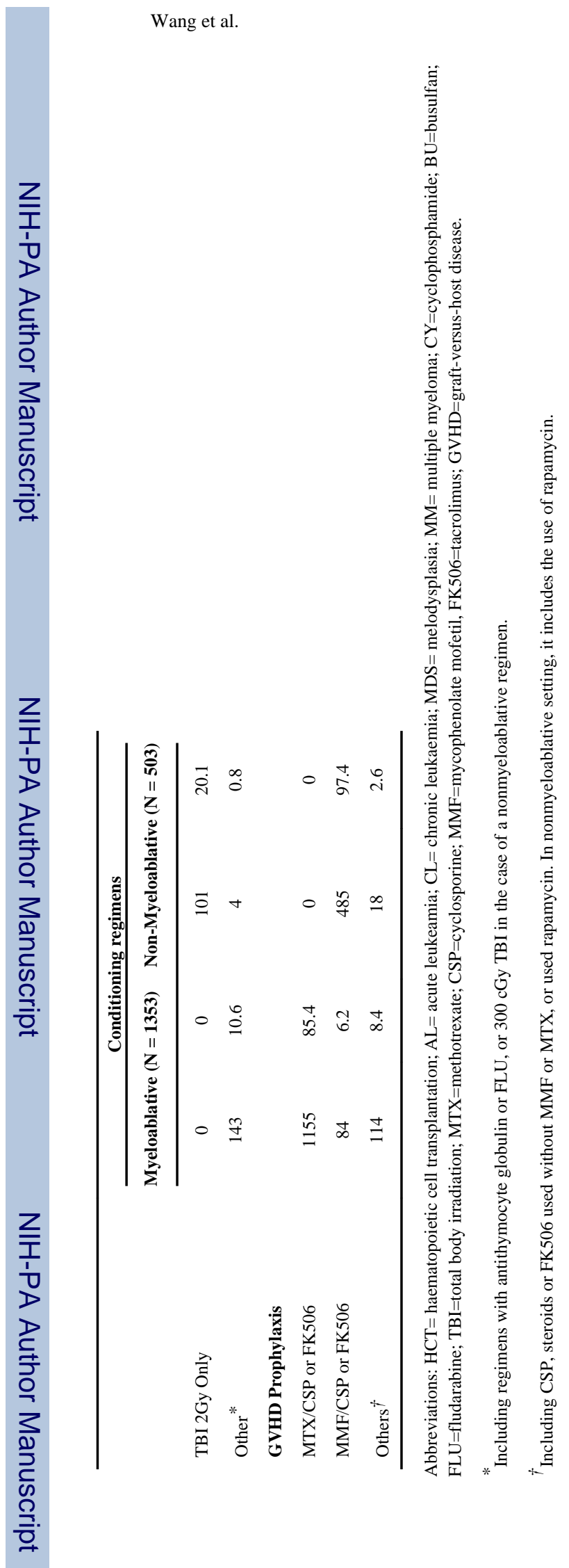

Br J Haematol. Author manuscript; available in PMC 2011 April 1. 
